\title{
XXIV. An attempt to determine the definite and simple proportions, in which the constituent parts of unorganic substances are united with each other
}

Jacob Berzelius M.R.A.

To cite this article: Jacob Berzelius M.R.A. (1813) XXIV. An attempt to determine the definite and simple proportions, in which the constituent parts of unorganic substances are united with each other, Philosophical Magazine Series 1, 42:184, 135-139, DOI: 10.1080/14786441308638299

To link to this article: http://dx.doi.org/10.1080/14786441308638299

曲 Published online: 27 Jul 2009.

Submit your article to this journal ¿

ЏII Article views: 3

Q View related articles $\square$ 


\section{[ 135 ]}

XXIV. An Attempt to determine the definite and simple Proportions, in which the constituent Parts of unorganic Substances are united with each other. By JACOB BERzELIus, Professor of Medicine and Pharmacy, and M.R.A. Stockholm.

(Continued from p. 44.)

XVIII. Lime.

$I_{N}$ the description of my earlier experiments on the decomposition of the alkalis, 1 have shown that in such decompositions the magnitude of the effect depends entirely upon that of the electricity discharged, and I have described the most effectual arrangement of the apparatus. In the decomprsition of the alkaline earths the case is totally different. The solutions in water can never be so much concentrated as those of the alkalis; the quantity of the earth which comes at each instant within the compass of the operation of the battery is consequently very small in proportion to that of the water, and the greatest part of the power of the battery is employed on the water. While therefore in the analysis of potass or soda we are obliged, in order'to diminish the intensity of the discharge, to extend the surface of the quicksilver, in that of the earths we are obliged to confine it, in order to increase the intensity of the operation, since only so much of it as is left after the decomposition of the water can operate on the earths. On this account a very slight addition of muriatic acid is favourable to their decomposition; while, if a larger quantity were added, the force of the battery would be consumed in the useless separation of the earth from the acid, leaving the intimate composition of the earth unaltered. Hence also we see why the proper earths are wholly incapable of being decomposed by the electric column. As soon as the first powerful action of the battery has subsided, it operates very little on the earths, and decomposes the water only.

The decomposition of lime I effected in a little glass dish, into which I poured some quicksilver, and on it a thin liquid paste of newly slaked lime. An iron wire formed a connection between the quicksilver and the negative pole of the column, and from its positive pole a wire of platina was introduced into the lime liquor. If this substance was too thick, the gas which was formed raised it up, so that it no longer touched the conductor.

The amalgam of calcium does not differ in its appearance from pure quicksilver; but it has little fluidity, and is duc- 
tile, like an amalgam of platina. In the air it instantly blackens, and becomes covered with a thick crust. When it is saturatel, it stiffens after some time into a black porous mass, from which some globules of quicksilver may be pressed out; the remainder is a combination of the protoxide of mercury with lime, resembling the brown crust which forms on the residuum left afrer the distillation of the amalgam of potassium, and the lime may be dissolved out of it by water, without a trace of further uxidation, the protoxide only remaining. That in these experiments the quicksilver should be oxidated together with the calcium and potassium, would not have been expected: but :his circumstance must evidently be attributed to the want of a substance with which the newly oxidated basis may enter into combination; and this substance is here, in the absence of water, the protoxide of mercury, which on the contrary is not formed when the base is oxidated in water.

If we distil the amalgam of calcium in a small apparatus filled with hydrogen gas, we obtain after a low red heat a metal with a silvery lustre, which when cold is very brittle, and contains much quicksilver. This metal does not blacken in the air, but becomes covered with a white crust of caustic lime, which at last retains a globule of quicksilver in the middle. If we throw the amalgam into water, lime is formed, with an evolution of hydrogen gas free from smell. If we drop muriatic acid or sal ammoniac into the water, the evolution of gas is increased, and the hydrogen assumes a strong disagreeable smell, as when irun or zine is dissolved in muriatic acid. I have observer no smell in hydrogen gas, even when it is evolved with great violence from the distilled amalgam of calcium; the acid must couscquently cooperate in the production of the smeil; but how does this happen? To assume, that the calcium is dissolved in hydrogen, seems not to be sufficient for the explanation, since the smell ought in this case to be more perceptible without the addition of the acid. When the water is saturated with lime, the evolution of gas is almost entirely interrupted, until more water is added.

The experiments for the detcrmination of the quantity of oxygen in lime are still less to be depended on than those which $I$ have related with regard to the fixed alkalis, and for the same reason, that $I$ have always had only very minute quantitics of the base to operate upon.

1.) An amalgam of calcium weighing 58.2 grammes lost in water $06 \mathrm{gr}$. To the solution carbonate of am. monia was added, and a precipitate of 145 grammes of car- 
bonate of lime was obtained. So that 56.4 parts of lime being contained in 100 of the carbonate; the $145 \mathrm{gr}$. correspond to 9818 of pure lime, which, according to this experiment, must consist of $73 \frac{r}{2}$ per cent. of the base and $26 \frac{1}{2}$ of oxyent.

2.) An amalgam of $53.535 \mathrm{gr}$. gave off 037 of calcium to, the water, and from this water lobtained with the car* bonate of anmonia 09 of carbonate of lime. This gives for lime 73 parts of the hase and 97 of oxyen.

3) An amalgam of $56.65 \mathrm{gr}$. which, in order to expel all possible moisture, had bren bested in an air tight verset, and then hastily pased through a capillary funnel, farnished to the water 0.435 of calcium. The lime water was satvrated with sulphuric acid, and evaporated and ignited in a golden crucible. It afforded 148 of gypsum, in which .0622 of lime is contained. According to this experiment, lime consists of 70 parts of base and 30 of oxygen.

Calculations conducted on the same principle with those by which the composition of the aikalis has been determined, give for that of lime a result not materially ai variance with these experiments. We have seen, in treating of the sulphuric acid, IIJ. A.) that dry gypsum is composed of about 58 parts of sulphuric acid and 42 of lime, or that 100 parts of sulphuric acid saturate 72.41 of lime. If these now contain $20^{\circ} 29$ parts of oxygen, they give for 100 parts of lime 28 of oxygen.

In order to calculate the composition of lime from its combination with the muriatic acid, I analysed the muriate of line.

a) Ten grammes of carbonate of lime were dissolved in muriatic acid in a glass flask, then dried and ignited until they were fused. The fused salt weighed $10.95 \mathrm{gr}$. But ten gr. of carbonate of lime contain $5 \cdot 64$ of lime; consequently 100 parts of fused muriate of lime consist of 48.54 of acid and $51 \cdot 46$ of lime.

b.) Some muriate of lime, which had been fused in a platina crucible, and weighed $3.01 \mathrm{gr}$, was dissolved in water. The solution wes uit perfectly clear, bu: was rendered so by a single small drop of very weak nitric acid. The precipitate by nitrate of silver weighed $7 \cdot 75 \mathrm{gr}$. wheth fused. This answers to 1.418 gr. of meratic acid, whence the muriate contains 48.1 of acid and 51.9 of lime.

This agrees pretty well with what has been already related; for wo know, from the experiments deseribed in the analysis of sal ammoniac, with what force the muriate of lime retains its water, and on this the greater proportion of muriatic acid found in the former experiments may possibiv depend. 
depend. I therefore consider the experiment on the precipitation as the most to be depended on, and according to this the muriate of lime consists of

$$
\begin{array}{lr}
\text { Muriatic acid ..... } 48.1 & 100 \cdot 0 \\
\text { Lime........ } & 51 \cdot 9
\end{array}
$$

If we expmine this result by calculation according to the quantity of baryta and lime, by which 100 parts of sulphuric acid are saturated, and the quantity of baryta required to neutralise 100 parts of muriatic acid, we have $194: 72^{\circ} 41=288^{\circ} 6: 107 \cdot 72$. Here then the calculation pretty nearly agrees with the experiment.

If now in these 107.9 parts of lime 30.49 of oxygen are contained, lime must conlain $28^{\circ} .967$ per cent. of oxygen. This being supposed correct, we have for lime

$$
\begin{array}{lr}
\text { Calcium } \ldots \ldots \ldots & 71.733 \\
\text { Oxygen } \ldots \ldots \ldots & 28.267
\end{array}
$$

\section{Baryta. Muriatic Acid.}

The foregoing experiments agreeing pretty well with the results of calculation, I believe that I may take for granted that bereafter calculations alone will be sufficient, when they are founded on the results of correct experiments: Thus, for example, in the case of baryta, the composition of which may be pretty easily calculated; since 100 parts of sulphuric acid suppose in 194 of baryta 20.29 of nxygen, haryta must consist of 10.46 oxygen and 89.54 barylium; or since 100 parts of muriatic acid suppose in 288.4 of baryta 30.49 of oxygen, baryta must consist of 10.575 oxygen and 89.435 barytium. The difference of these two results shows that the analyses are not yet arrived at a sufficient degree of perfection, but it may be hoped that in future this perfection will be more easily obtained. In the great number of analytical experiments which I have been obliged to emplov, in order to obtain some connected results, no man will be surprised if I have not always sucseeded in determining every figure of the numbers concerned with perfect accuracy.

Mav we not expect that the same proportions, which we have found to prevail in whole orders of compounds, must always subsist bewven the same substances, even in complicated mixtures, and in bodies of different natures? I conjecture that this question, after many repetitions of experiments, will he answered in the affirmative, although there may be some partial exceptions; as we have already seen in the analyses of the subsulphate and the sulphate of the oxide of iron, where the original proportions of the sulphur 
sulphur and iron were modified by those of the oxygen and iron, and underwent a change which I attempted to explain. It is besides more than probable, that if, for example, 100 parts of muriatic acid constantly require 30.49 of oxygen in the salts into which they enter, they do the same in all other definite combinations; so that 100 parts of muriatl acid take up the same quantity of oxygen in oxymuriatic acid gas, in the water chemically combined with dry muriatic acid gas, in the alcohol forming muriatic ether, in all animal substances with which the acid is capable of forming distinct combinations, and so forth. With respect to the oxymuriatic acid gas, it has long been known that in a low temperature it is completely condensed by metals, so 23 to form a salt, in which the metal exists as a protoxide; as it is also proved by Davy's excellent experiments, that the driest muriatic acid gas contains a definite quantity of water, which, when it is treated with potassium, produces so much potass as to saturate the acid. We therefore assume, upon good grounds, that in the oxymuriatic acid, as in salts, 100 parts of muriatic acid are combined with 30.49 of oxygen, and hence that the oxymaWiatic acid gas consists of

$$
\begin{aligned}
& \text { Muriatic acid...... } 76.63 \quad 100.00 \\
& \text { Oxvgen ........ 23.37 } 30.49
\end{aligned}
$$

And if water contains 12 per cent. of hydrogen, 100 parts of dry muriatic acid must take up 34.54 of water, ot muriatic acid gas must contain somewhat more than a quarter of water.

XX. Combinations of Hydrogen with Oxyghn and Sulphur.

Biot and Arago having determined, by weighing oxygen and hydrogen, that water consists of 11.7 of hydrogen and 83.3 oxygen, I thought it necessary to examine by experiments this result, which differs from the numbers commonly adopted. If the experiments which I have been able to make are not so fully sufficient for the purpose as I at first flattered myself, they may still deserve to be related, since their results cannot very materially differ from the truth.

I made use of distilled zinc, which I dissolved in sujphuric or muriatic acid, and suffering the hydrogen to escape by a tube filled with muriate of lime, I observed the weight lost by the apparatus. I have not however been able to obtain the zinc perfectly free from sulphur and lead, nor was the loss of weight precisely the same in different experiments. 